\title{
Energy gap studies on As-Sb-Se glasses
}

\author{
K NANDAKUMAR and JACOB PHILIP \\ Department of Physics, Cochin University of Science and Technology, Cochin 682022 , \\ India \\ MS received 19 August 1988; revised 2 November 1988
}

\begin{abstract}
Variation of optical energy gap $E_{0}$ with composition in several glasses belonging to the $\mathrm{As}-\mathrm{Sb}-\mathrm{Se}$ system have been studied. The photoacoustic technique, wellsuited for highly absorbing samples, has been used for the measurements. Results reported on the $\mathrm{As}_{x} \mathrm{Sb}_{5} \mathrm{Se}_{95-x}, \mathrm{As}_{x} \mathrm{Sb}_{10} \mathrm{Se}_{90-x}, \mathrm{As}_{x} \mathrm{Sb}_{15} \mathrm{Se}_{85-x}$ and $\mathrm{As}_{x} \mathrm{Sb}_{20} \mathrm{Se}_{80-x}$ glasses of the As-Sb-Se family are explained on the basis of the chemically ordered network model.
\end{abstract}

Keywords. Band gap energy; chalcogenide glasses; photoacoustics.

\section{Introduction}

Amorphous chalcogenide semiconductors have attracted much attention in recent years because of their established use as photoconductors and their potential use as the active components in threshold and memory switching devices (Adler 1977; Mott and Davis 1979; Savage 1972; Zallen 1983). Among the glass forming alloys of the group $\mathrm{A}_{x}^{\mathrm{V}} \mathrm{B}^{\mathrm{IV}}{ }_{100-x}$, the $\mathrm{As}_{x} \mathrm{Se}_{100-x}$ family has been studied extensively (Lucovsky and Hayes 1979; Nemanich et al 1978; Street et al 1978). But there are not many studies on the effect of the replacement of As in the As Se system by other elements. The results of the study of the low temperature elastic behaviour of As-Sb-Se glasses have been reported earlier (Gopal et al 1987). The composition dependence on glass transition temperature $T_{g}$, crystallisation temperature $T_{c}$, peak temperature of crystallisation $T_{p}$, crystallisation enthalpy $\Delta H_{\mathfrak{c}}$ etc. have been studied using differential scanning calorimetry (Mahadevan et al 1986; Giridhar and Mahadevan 1982).

Here we report the results of the measurement of the variation of the band gap energy $E_{0}$ with composition in glasses of the As-Sb-Se system using the photoacoustic (PA) technique. Such investigations will greatly help in selecting materials of the desired energy gap and optical absorption properties for special applications.

The compositions of the $\mathrm{As}_{x} \mathrm{Sb}_{y} \mathrm{Se}_{100-x-y}$ glasses studied (table 1) can be classified into four groups depending on the $\mathrm{Sb}$ content. In each group, the compositions (As, $\mathrm{Sb})_{40} \mathrm{Se}_{60}$ fall along the pseudobinary section $\mathrm{As}_{2} \mathrm{Se}_{3}-\mathrm{Sb}_{2} \mathrm{Se}_{3}$ and represents the so-called 'stoichiometric' composition.

\section{Experimental}

Bulk glasses of the As-Sb-Se system have been prepared by the usual melt-quenching technique. High purity $(5 \mathrm{~N})$ elements in appropriate atomic percent proportions are sealed in quartz ampoules under a vacuum of $\approx 10^{-3}$ torr. The sealed ampoules are heated in a furnace for nearly $24 \mathrm{~h}$. During heating the ampoules are rotated continuously to ensure homogenization of the melt which is then quenched in ice 
Table 1. Measured values of the optical energy gap $E_{0}$ of $\mathrm{As}_{x} \mathrm{Sb}_{y} \mathrm{Se}_{100-x-y}$ glasses.

\begin{tabular}{|c|c|c|c|}
\hline System & $x$ & Sample & $E_{0}(\mathrm{eV})$ \\
\hline \multirow{5}{*}{$\mathrm{Ax}_{x} \mathrm{Sb}_{20} \mathrm{Se}_{80-x}$} & 10 & $\mathrm{As}_{10} \mathrm{Sb}_{20} \mathrm{Se}_{70}$ & 1.557 \\
\hline & 15 & $\mathrm{As}_{15} \mathrm{Sb}_{20} \mathrm{Se}_{65}$ & $1 \cdot 460$ \\
\hline & 20 & $\mathrm{As}_{20} \mathrm{Sb}_{20} \mathrm{Se}_{60}$ & $1 \cdot 422$ \\
\hline & 25 & $\mathrm{As}_{25} \mathrm{Sb}_{20} \mathrm{Se}_{55}$ & $1 \cdot 410$ \\
\hline & 30 & $\mathrm{As}_{30} \mathrm{Sb}_{20} \mathrm{Se}_{50}$ & $1 \cdot 386$ \\
\hline \multirow{5}{*}{$\mathrm{As}_{x} \mathrm{Sb}_{15} \mathrm{Se}_{85-x}$} & 15 & $\mathrm{As}_{15} \mathrm{Sb}_{15} \mathrm{Se}_{70}$ & 1.640 \\
\hline & 20 & $\mathrm{As}_{20} \mathrm{Sb}_{15} \mathrm{Se}_{65}$ & $1 \cdot 540$ \\
\hline & 25 & $\mathrm{As}_{25} \mathrm{Sb}_{15} \mathrm{Se}_{60}$ & 1.495 \\
\hline & 30 & $\mathrm{As}_{30} \mathrm{Sb}_{15} \mathrm{Se}_{55}$ & 1.477 \\
\hline & 35 & $\mathrm{As}_{35} \mathrm{Sb}_{15} \mathrm{Se}_{50}$ & 1.447 \\
\hline \multirow{5}{*}{$\mathrm{As}_{x} \mathrm{Sb}_{10} \mathrm{Se}_{90-x}$} & 20 & $\mathrm{As}_{20} \mathrm{Sb}_{10} \mathrm{Se}_{70}$ & 1.643 \\
\hline & 25 & $\mathrm{As}_{25} \mathrm{Sb}_{10} \mathrm{Se}_{65}$ & 1.606 \\
\hline & 30 & $\mathrm{As}_{30} \mathrm{Sb}_{10} \mathrm{Se}_{60}$ & 1.570 \\
\hline & 35 & $\mathrm{As}_{35} \mathrm{Sb}_{10} \mathrm{Se}_{55}$ & $1 \cdot 556$ \\
\hline & 40 & $\mathrm{As}_{40} \mathrm{Sb}_{10} \mathrm{Se}_{50}$ & $1 \cdot 540$ \\
\hline \multirow{5}{*}{$\mathrm{As}_{x} \mathrm{Sb}_{5} \mathrm{Se}_{95-x}$} & 25 & $\mathrm{As}_{25} \mathrm{Sb}_{5} \mathrm{Se}_{70}$ & 1.762 \\
\hline & 30 & $\mathrm{As}_{30} \mathrm{Sb}_{5} \mathrm{Se}_{65}$ & 1.694 \\
\hline & 35 & $\mathrm{As}_{35} \mathrm{Sb}_{5} \mathrm{Se}_{60}$ & $1 \cdot 638$ \\
\hline & 40 & $\mathrm{As}_{40} \mathrm{Sb}_{5} \mathrm{Se}_{55}$ & 1.627 \\
\hline & 45 & $\mathrm{As}_{45} \mathrm{Sb}_{5} \mathrm{Se}_{50}$ & $1 \cdot 610$ \\
\hline
\end{tabular}

water to obtain the glass samples. The quenching rate is about $200 \mathrm{~K} / \mathrm{s}$. The amorphous nature of the samples has been checked by $\mathrm{X}$-ray diffractometry.

The photoacoustic (PA) spectrometer used for the optical absorpion studies is described elsewhere (Madhusoodanan et al 1988). The optical absorption coefficient is directly proportional to the PA signal amplitude (Rosencwaig 1980). The PA signal amplitude as a function of the wavelength of the incident radiation is recorded. The optical energy gap $E_{0}$ is determined from the normalized PA signal amplitude vs. incident wavelength plot (Weast 1977). The normalized PA spectra of two typical samples are shown in figure 1. Similar plots have been recorded for all the samples investigated.

\section{Results and discussion}

The measured energy gap values for 20 glasses belonging to the As-Sb-Se family are tabulated in table 1. The variation of $E_{0}$ with compositon for the four groups of glasses viz. $\mathrm{As}_{x} \mathrm{Sb}_{5} \mathrm{Se}_{95-x}, \mathrm{As}_{x} \mathrm{Sb}_{10} \mathrm{Se}_{90-x}, \mathrm{As}_{x} \mathrm{Sb}_{15} \mathrm{Se}_{85-x}$ and $\mathrm{As}_{x} \mathrm{Sb}_{20} \mathrm{Se}_{80-x}$ are shown in figure 2. The variation of $E_{0}$ with $x$ in $\mathrm{As}_{x} \mathrm{Se}_{100-x}$ glasses is also shown in the same figure (Madhusoodanan and Philip 1988) for comparison. From this figure it is clear that for a particular Sb concentration, as the As content increases (i.e. Se content decreases) $E_{0}$ decreases and shows a marked change in its rate of decrease at a particular concentration at which the As content and $\mathrm{Sb}$ content together is 40 atomic percent. This is the stoichiometric composition for the As-Sb-Se system of glasses. The rate of decrease in $E_{0}$ is higher for compositions with $(x+y)<40$ than for those with $(x+y)>40$. For the $\mathrm{As}_{x} \mathrm{Se}_{100-x}$ family of glasses, $E_{0}$ shows a 


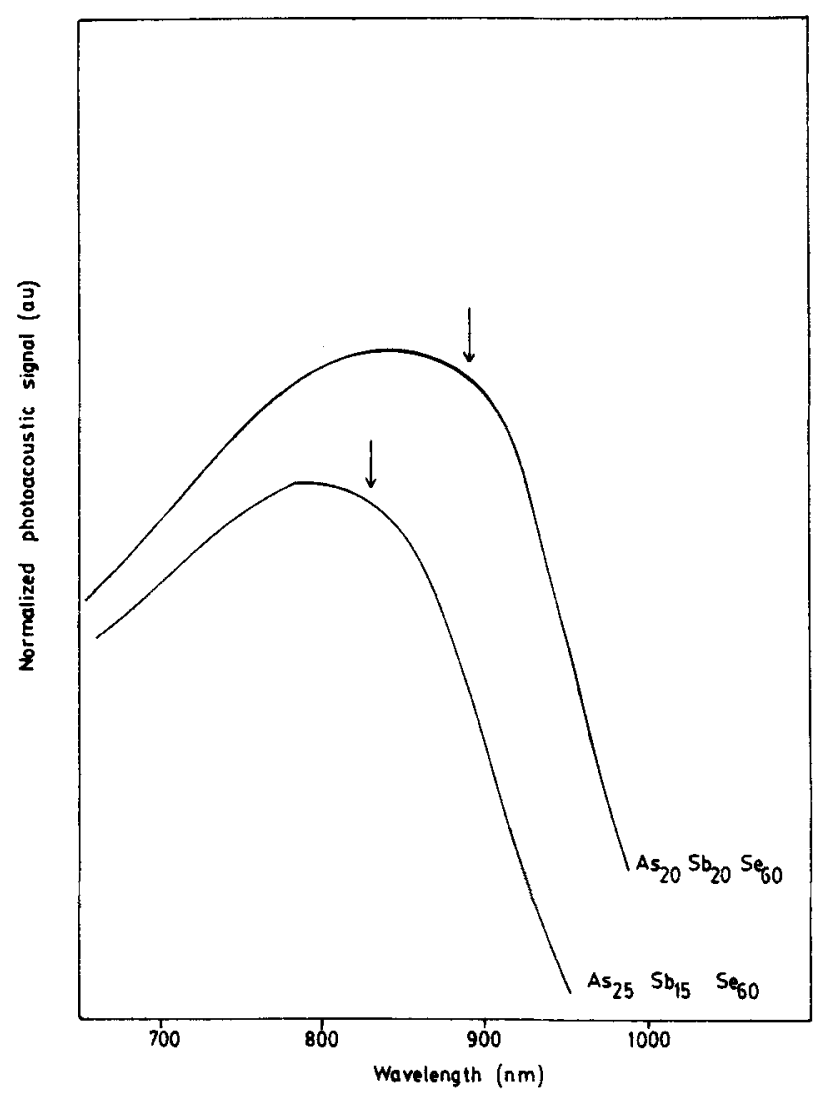

Figure 1. Normalized photoacoustic (PA) signal vs. wavelength for two typical glasses.

threshold minimum value at $x=40$, which is the stoichiometric composition $\mathrm{As}_{2} \mathrm{Se}_{3}$ (Madhusoodanan and Philip 1988). The behaviour observed in the As-Sb-Se family of glasses for compositions with $(x+y)<40$ is very much similar to that observed for $x<40$ in $\mathrm{As}_{x} \mathrm{Se}_{100-x}$ glasses but for compositions with $(x+y)>40$, it is very much different from $\mathrm{As}_{x} \mathrm{Se}_{100-x}$ glasses with $x>40$.

The dotted line in figure 2 shows the variation of $E_{0}$ along the stoichiometric compositions. It can be seen that with increase in $\mathrm{Sb}$ content $E_{0}$ decreases gradually.

The observed behaviour of the As-Sb-Se family of glasses can be explained on the basis of chemical bonding between atoms and changes in the short-range order that occurs in the glass network with increase in $\mathrm{Sb}$ concentration. For $\mathrm{As}_{x} \mathrm{Se}_{100-x}$ with $0<x<40$ the short-range order is well defined and is similar to that of the parent glass: Se is two-coordinated and As is three-coordinated. The chemical order is maintained for As atoms, each of which (as in $\mathrm{As}_{2} \mathrm{Se}_{3}$ ) is bonded to three $\mathrm{Se}$ atoms. The composition dependence is brought about by the occupation of $\mathrm{Se}$ atoms in favourable positions in the network (Zallen 1983). In the As-Se system there are $\mathrm{As}-\mathrm{As}, \mathrm{As}-\mathrm{Se}$ and $\mathrm{Se}-\mathrm{Se}$ bonds or the $\mathrm{Se}$ atomic chains are interconnected with As atoms. In the Se rich glasses the network is dominated by $\mathrm{Se}$ atomic chains and addition of As atoms results in the formation of branching 


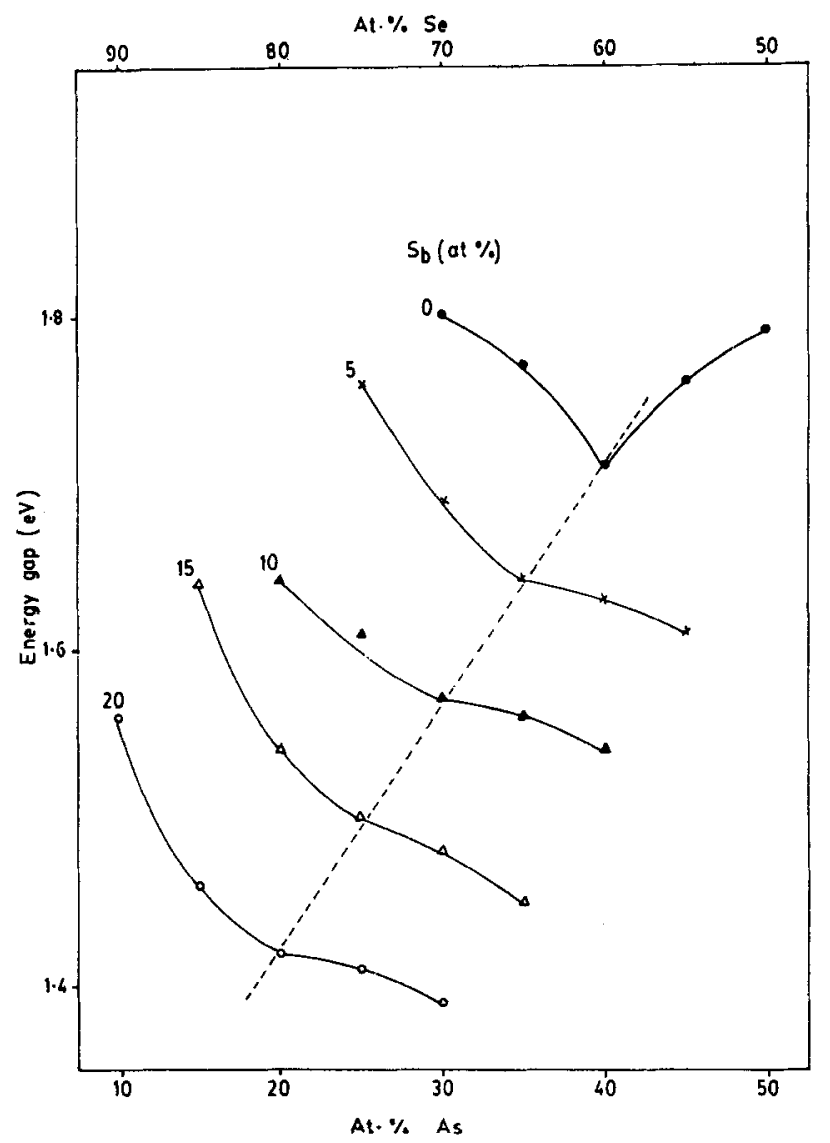

Figure 2. $E_{0}$ vs. composition for $A s_{x} \mathrm{Sb}_{y} \mathrm{Se}_{100-x-y}$ glasses. - $\mathrm{As}_{x} \mathrm{Se}_{100-x}, \quad 0-$ $\mathrm{As}_{x} \mathrm{Sb}_{20} \mathrm{Se}_{80-x}, \triangle-\mathrm{As}_{x} \mathrm{Sb}_{15} \mathrm{Se}_{85-x}, \Delta-\mathrm{As}_{x} \mathrm{Sb}_{10} \mathrm{Se}_{90-x}, \times \mathrm{As}_{x} \mathrm{Sb}_{5} \mathrm{Se}_{95-x}$

chains on 3-fold coordinated As atoms in the basic structural units. The two coordinated $\mathrm{Se}$ atoms form $(\mathrm{Se})_{n}$ chains or $(\mathrm{Se})_{8}$ rings and the addition of 3 coordinated As atoms breaks these chains or rings to satisfy its coordination number and form a very complex network structure.

With the introduction of Sb atoms, the Se atom chains get interconnected with both $\mathrm{As}$ and $\mathrm{Sb}$ atoms. Based on the chemically ordered network (CON) model (Lucovsky and Hayes 1979), the As-Sb-Se glass can be thought of as being made up of completely cross-linked three-dimensional structural units of $\mathrm{As}_{2} \mathrm{Se}_{3}$ and $\mathrm{Sb}_{2} \mathrm{Se}_{3}$ with either $\mathrm{As}$ or $\mathrm{Se}$ in excess. Apart from $\mathrm{As}-\mathrm{Se}, \mathrm{Sb}-\mathrm{Se}$ and $\mathrm{Se}-\mathrm{Se}$ bonds in the network, As-As and $\mathrm{Sb}-\mathrm{Sb}$ bonds also will be involved in forming the glass.

The bond energies of $\mathrm{As}-\mathrm{Se}, \mathrm{Sb}-\mathrm{Se}, \mathrm{Se}-\mathrm{Se}, \mathrm{As}-\mathrm{As}$ and $\mathrm{Sb}-\mathrm{Sb}$ bonds are 52, 51, 49,46 and $42 \mathrm{kcal} / \mathrm{mol}$ respectively (Das et al 1974). The As-As bond energy is lower than the As-Se bond energy. With decreasing Se content in As rich glasses the $\mathrm{Sb}_{2} \mathrm{Se}_{3} / \mathrm{As}_{2} \mathrm{Se}_{3}$ ratio progressively increases resulting in a decrease in average bond energy and a corresponding decrease in $E_{0}$. For the Se rich glasses the $\mathrm{As}_{2} \mathrm{Se}_{3}$ content is larger than the $\mathrm{Sb}_{2} \mathrm{Se}_{3}$ content and results in the observed increase in optical energy gap. When the atomic percentages of $\mathrm{As}$ and $\mathrm{Sb}$ become equal to 20 (critical composition), the number of $\mathrm{As}-\mathrm{Se}$ and $\mathrm{Sb}-\mathrm{Se}$ bonds are equal. Since As 
and $\mathrm{Sb}$ are isovalent one cannot expect any drastic change in the basic structure of the glass by replacing $\mathrm{As}$ by $\mathrm{Sb}$. However as the $\mathrm{Sb}$ concentration increases the probability for the formation of $\mathrm{Sb}-\mathrm{Sb}$ and $\mathrm{Sb}-\mathrm{Se}$ bonds increases. Hence the average bond energy of the compound is reduced which effectively reduces $E_{0}$. These arguments agree well qualitatively with the observations.

\section{Acknowledgement}

The authors thank the Department of Atomic Energy (BRNS) for financial support.

\section{References}

Adler D 1977 Sci. Am. 23636

Das G C, Platakis N S and Bever M B 1974 J. Non-cryst. Solids 1530

Giridhar A and Mahadevan S 1982 J. Non-cryst. Solids 51305

Gopal E S R, Mukundan T S, Philip J and Satish S 1987 Pramana-J. Phys. 28471

Lucovsky G and Hayes T M 1979 in Amorphous semiconductors (ed.) M H Brodsky (Berlin: SpringerVerlag) p. 215

Madhusoodanan K N and Philip J $1988 \mathrm{~J}$. Mater. Sci. (communicated)

Madhusoodanan K N, Philip J, Parthasarathy G, Asokan S and Gopal E S R 1988 Philos. Mag. B58 123

Mahadevan S, Giridhar A and Singh A K 1986 J. Non-cryst. Solids 8811

Mott N F and Davis E A 1979 Electronic processes in non-crystalline materials (Oxford: Clarendon)

Nemanich R J, Connell G A N. Hayes T M and Street R A 1978 Phys. Rev. $B 186900$

Rosencwaig A 1980 Photoacoustics and photoacoustics spectroscopy (New York: Wiley)

Savage J A 1972 J. Mater. Sci. 764

Street R A, Nemanich R J and Connell G A N 1978 Phys. Ret. B18 6915

Weast R C 1977 CAC handbook of chemistry and physics (Ohio: CRC Press)

Zallen R 1983 The physics of amorphous solids (New York: Wiley) 